\title{
British Infertility Counselling Association
}

\section{Susan Quilliam}

Writer, Broadcaster, Consultant and Trainer, Cambridge, UK

\section{Correspondence to}

Ms Susan Quilliam,

Cambridge, UK;

susan@susanquilliam.com;

http://www.susanquilliam.com

Received 24 September 2014 Accepted 24 September 2014
CrossMark

To cite: Quilliam S. J Fam Plann Reprod Health Care 2015;41:154-155.

\section{WHO ARE YOU?}

The British Infertility Counselling Association (BICA) is the only professional association in the UK for infertility counsellors. We represent the interests, views and needs of members actively involved in infertility counselling and of professionals in related research. We support our members in a variety of ways, and through doing so we support the total well-being of people with fertility problems.

\section{WHY, AND HOW, WERE YOU FOUNDED?}

Jennie Hunt, who had been working as a counsellor in the assisted conception field in Australia, returned to the UK in 1985. She was astonished to find that it was difficult to identify counsellors in the 25 UK infertility clinics at that time, and that little networking was happening between those who could be identified. Jennie set about trying to contact counsellors by writing to each clinic. Twenty of the 25 clinics responded and over $60 \%$ said that they offered counselling; however, this was usually delivered by a clinician or nurse, with only five clinics using a specifically trained counsellor.

Jennie and the founding committee she gathered around her were concerned that there was no support for, or networking between, infertility counsellors. They also argued against the appointment of non-counsellors to counselling positions and fought for a high standard of training and guidance for those filling those positions. In addition, they realised that there was no co-ordinated voice speaking about infertility from the counselling perspective, and that in order to make such a voice heard there needed to be a recognised organisation of infertility counsellors.

As a result, Jennie Hunt, along with others, set up BICA in 1988. By 1990 we had achieved charitable status and had a board of trustees; then we started the serious task of developing training that would give infertility counselling a coherent professional identity through recognised qualifications and accreditation.

\section{WHO ARE YOUR MEMBERS AND WHAT NEED DO THEY MEET?}

Our members are infertility counsellors who work in the National Health Service, in private clinics and also independently. We draw from a variety of professions including psychologists, nurses and social workers, as well as those who originally came from the counselling discipline.

Our members all work with clients who seek support for fertility problems, whether or not such clients choose to have medical intervention; with those undergoing treatment involving donor egg, donor sperm and donor embryos and with the donors themselves; with those using surrogacy and with the surrogates themselves.

Many of these clients typically need huge support. Not only does infertility cause enormous distress - not all of which is resolved even after a birth - but there can also be implications to treatment, particularly treatments involving donation or surrogacy. As well as offering support, our members provide 'implications counselling' to help those involved in these treatments to explore the social, emotional, legal, ethical and psychological implications and to choose the best ways forward.

\section{WHAT SERVICES DO YOU OFFER MEMBERS?}

As well as constantly advocating and advancing the role of counselling support for all involved in the infertility process, we also establish representation on infertility-related forums, conferences and meetings, and have a voice in national policy- and decision-making. 
In addition, we offer members professional training and accreditation; hold seminars, workshops and forums on relevant issues; issue regular updates on related topics; publish the Journal of Fertility Counselling three times a year which is free for members; and create professional support opportunities for members through our forums and regional meetings. We also conduct surveys to research infertility issues in order to understand the experience of people having to deal with them and to raise professional and also public awareness. Our website offers clients themselves a 'Find a Counsellor' facility.

\section{WHAT'S BEEN YOUR BIGGEST TRIUMPH OVER THE YEARS?}

In 2013 we celebrated our 25th anniversary and this quarter century has brought a number of triumphs. We are particularly proud of our original influence on the Human Fertilisation and Embryology Act (1990) and our representation on the Kings' Fund Committee, which advised the Government about counselling provision in infertility clinics. Over the years we have worked to constantly clarify the role of infertility counselling, developed guidelines for practice and set up the training and accreditation programme. In addition, we have since our inception kept our professional journal running without any breaks in publication.

\section{WHAT'S BEEN YOUR BIGGEST PROBLEM?}

We do sometimes have difficulty in convincing clinics and senior clinicians of the value of infertility support delivered by trained professional counsellors. In addition, we know that many clients want counselling, but are either not offered it, have limits set on the number of sessions offered, or have to fund it themselves; proper therapeutic support for infertility issues is not universal. In addition, we ourselves are financed almost entirely through membership subscriptions, so there are limits to the work we can do.

\section{WHAT ARE YOUR MOST EXCITING PLANS AND BIGGEST HOPES FOR THE FUTURE?}

We have a number of plans in the pipeline. We aim to expand our website to increase member involvement, and to widen our training programme to include the training of teams. We are closely involved in work to manage effectively and sensitively the process of opening the Donor Register. We especially hope that satisfactory funding will be provided to resource a proper intermediary service for donor-conceived people to receive counselling and support in learning about their origins, should they so wish, and further support and counselling for all parties to donation to facilitate successful face-to-face contact when appropriate.

\section{WHAT DO YOU WANT TO SAY TO JFPRHC READERS?}

The psychosocial components of infertility issues are very significant for everyone involved. So if your role involves working with these issues, please give patients, donors and surrogates access to the support of a skilled infertility counsellor. If you are an infertility counsellor yourself, please join us at BICA.

\section{FURTHER INFORMATION}

\begin{tabular}{|c|c|}
\hline Who: & Infertility Counselling Association \\
\hline $\begin{array}{l}\text { Address: } \\
\text { Website: }\end{array}$ & $\begin{array}{l}33 \text { Goldington Street, London NW1 1UE, UK } \\
\text { http://www.bica.net }\end{array}$ \\
\hline Contact: & $\begin{array}{l}\text { For clients, details of how to find a BICA } \\
\text { counsellor can be found on our website in } \\
\text { the 'Find a Counsellor' section. For infertility } \\
\text { counsellors, details of training, events and } \\
\text { other useful information are available on } \\
\text { our website. }\end{array}$ \\
\hline
\end{tabular}

\section{Competing interests None.}

Provenance and peer review Not commissioned; internally peer reviewed.

Editor's note This article is one in a series of occasional articles on key health organisations worldwide. The Journal would be pleased to hear from other organisations, particularly those based outside the UK, which would like to be similarly profiled.

\section{LETTERS TO THE EDITOR}

Letters to the Editor are welcome and generally should not exceed 600 words or cite more than five references. For comments on material published in the most recent issue of the Journal, correspondence should be received within 4 weeks of dispatch of that Journal to be in time for inclusion in the next issue. When submitting letters correspondents should include their job title(s) and their work affiliation(s)/contact address(es). A statement on competing interests should also be submitted for all letters. Letters may be submitted to the Journal Editor or to the Journal Editorial Office (details on the Editorial Board page). 